\title{
A linguagem teleológica nas Ciências Biológicas: uma proposta de intervenção didática sobre o tema polinização
}

\author{
The teleological language in Biological Science: a proposal for a didactic \\ intervention on pollination
}

\author{
Giselle Alves Martins ${ }^{1}$, Fernanda da Rocha Brando²
}

1- Laboratório de Epistemologia e Didática da Biologia, Programa de Pós-graduação em Biologia Compara, Faculdade de Filosofia, Ciências e Letras de Ribeirão Preto, Universidade de São Paulo, Ribeirão Preto, São Paulo, Brasil.

2- Laboratório de Epistemologia e Didática da Biologia, Departamento de Biologia, Faculdade de Filosofia, Ciências e Letras de Ribeirão Preto, Universidade de São Paulo, Ribeirão Preto, São Paulo, Brasil.

\section{Resumo}

Introdução: Teleologia pode ser entendida como parte da Filosofia Natural que explica os fins das coisas, atualmente entendida como a ideia de que algumas coisas podem ser explicadas pelo apelo à sua finalidade, objetivo ou função. Nos estudos das Ciências Biológicas esse tipo de explicação pode ser considerado problemática por possibilitar visões equivocadas de processos evolutivos. Objetivo: Apresentar diferentes visões sobre a ideia de Teleologia, discutindo formas de explicações científicas e filosóficas utilizando o fenômeno da polinização como modelo biológico. E, ao final propor uma atividade didática para o ensino superior a fim de suscitar reflexões sobre essas questões. Metodologia: Foram utilizadas fontes primárias de textos de filósofos para o entendimento de diferentes visões sobre Teleologia. Para construção da sequência didática foram utilizados aspectos pedagógicos e epistemológicos, considerando as concepções de pesquisadores, alunos e professores no processo de construção do conhecimento. Resultados: A proposta discute diferentes pontos de vista sobre um mesmo fenômeno e permite reflexões sobre o processo de ensino-aprendizagem que considera a natureza da ciência sob uma abordagem filosófica-histórica. A proposta da atividade didática permite que esse tipo de abordagem possa ser utilizado por professores para sensibilização de biólogos em processo de formação inicial sobre a utilização desses termos em sala de aula. Conclusão: A leitura da exposição teórica permite entender a necessária redução no uso de termos teleológicos no ensino de fenômenos biológicos. Além disso, este estudo se apresenta como base para implementação de uma intervenção didática, viabilizando reflexões conscientes, considerando inserções tanto históricas quanto epistemológicas.

Palavras-chave: Epistemologia; Didática da Biologia; Formação de professores; Proposta didática 


\section{Abstract}

Introduction: Teleology can be understood as part of the Natural Philosophy that explains the usefulness of things, currently understood as the idea that some things can be explained by the appeal to its purpose, objective or function. In the Biological Sciences studies this type of explanation can be considered problematic because it allows misplaced perspectives concerning the evolutionary processes. Goals: To present different perspectives on the idea of teleology, discussing the scientific and philosophical explanations using the phenomenon of pollination as a biological model. Moreover, for didactic purposes an activity for higher education in order to stimulate reflections on these issues is proposed. Methodology: Philosophers studies were used as primary sources in order to understand the different perspectives in Teleology. For the construction of a didactic sequence, both pedagogical and epistemological aspects were considered considering the conceptions of researchers, students and teachers in the process of knowledge construction. Results: The proposal discusses different points of view on the same phenomenon and allows critical thinking on the teaching-learning process considering the nature of the scientific knowledge behind the philosophical-historical approach. The didactic activity proposal allows this type of approach to be used by teachers in order to raise awareness among biologists in the initial training process on the use of these terms in the classroom. Conclusion: The theoretical exposition grants the understanding of the necessary reduction of teleological terms in the teaching of biological phenomena. In addition, this study presents a basis for the implementation of a didactic intervention, allowing critical thinking, considering both historical and epistemological insertions.

Keywords: Epistemology, Didactics in Biology, Teacher training, Didactic proposal

\section{Introdução}

O presente artigo tem por objetivo apresentar algumas ideias sobre Teleologia, discutindo formas de explicações científicas e filosóficas sobre o fenômeno biológico polinização.

Quando a Filosofia recorre à Biologia para apoiar suas posições sobre temas filosóficos tradicionais, a extensa literatura sobre teleologia é um caso em questão ${ }^{1}$. Por exemplo, o termo "função" é ambíguo e utilizado em várias teorias e discursos científicos e filosóficos. No entanto, pode apresentar vários problemas de entendimento devido à pluralidade de ideias quando aplicado à Biologia, pois pode estar associado a um tipo particular de explicação sobre como algo existe e como sua forma é determinada por uma característica funcional ${ }^{2}$ (No presente estudo as palavras "algo" e "item" referem-se à sistemas biológicos, podendo ser exemplificado como um ser vivo, um órgão deste organismo, uma população ou um ecossistema). Explicações que têm como intenção esclarecer a existência, a forma, a distribuição ou a localização de algo, referindo-se aos estados futuros que esse algo pode vir a ter, refere-se à Teleologia.

Um dos primeiros usos da palavra "Teleologia" é atribuído ao filósofo Christian Wolff (1679-1754), em 1728 , que a definiu como parte da filosofia natural que explica os fins das coisas ${ }^{3}$.

O uso de argumentos teleológicos para explicar as características dos seres vivos era comum antes da aceitação da teoria da seleção natural ${ }^{4}$. A busca por explicações finalistas para os fenômenos naturais é reconhecida desde o pensamento grego. O termo "teleologia" deriva do grego em que telos significa objetivo, final ${ }^{5}$. De um modo geral, o pensamento dos filósofos pré-socráticos não era teleológico, eles buscavam explicações com base na constância da natureza e a existência de regularidades que depois foram denominadas "leis naturais"

Segundo Mayr, desde a antiguidade, existiam diversas visões de mundo no sentido finalista, em que tudo devia ter um significado e um propósito. No entanto, acreditava-se que havia um "deus" responsável pelas leis da natureza ${ }^{6}$.

Na época de Sócrates (469 a.C. - 399 a.C.) era comum a ideia de que tudo no mundo seria planejado para algum propósito. Sócrates adotava uma abordagem teleológica, pois considerava que as partes dos corpos, por exemplo, eram feitas para determinadas finalidades, planejadas para isso por uma divindade ${ }^{3}$.

Platão (429/427 a.C. - 348/347 a. C.) também atribuía primazia à determinação do propósito das coisas de acordo com as intenções de um planejador bondoso, sábio e providente ${ }^{3}$.

Em Aristóteles (384 a.C. - 322 a.C.), houve uma mudança de pensamento. Essa mudança seria devido às causas finais que direcionavam o objeto ou fenômeno particular para um objetivo último, as coisas no mundo empírico "se esforçavam" [strive] para atingir uma finalidade última ${ }^{6}$. Para Aristóteles existiam quatro tipos de causas: material, eficiente, formal e final. A causa final, especificamente, mostrava como ele acreditava na existência de finalidades na natureza. Entretanto, ao contrário de Platão e Sócrates, para Aristóteles não existia um planejador que tivesse estruturado o universo e os 
seres para adequá-los a essas finalidades, mas uma adequação quase perfeita dos seres naturais às suas necessidades e atividades: "a natureza não faz nada em vão"7. No entanto, ele afirmava que nem sempre a natureza atingia a perfeição ${ }^{7}$.

Em um contexto de estudos contemporâneos, a Teleologia consiste no uso de "causas finais" para explicar os fenômenos e o pensamento teleológico teria influenciado a Biologia provavelmente como nenhuma outra ideologia ${ }^{8}$. Atualmente Teleologia é a ideia de que algumas coisas podem e devem ser explicadas pelo apelo à sua finalidade ou ao objetivo ou função de algo 9 .

No entanto, algumas críticas são tecidas em relação ao uso desse tipo de linguagem que indica certo "propósito" dos fenômenos naturais. Muitas dessas críticas na Biologia são feitas por alguns estudiosos ${ }^{10,11}$, principalmente, devido a três motivos: I) explicações teleológicas envolvem questões teológicas e metafísicas e não devem ser usadas nas ciências; II) a causalidade teleológica é problemática por recorrer aos eventos futuros, com um fim, enquanto causalidade normal recorre simultaneamente a eventos passados; III) o antropomorfismo, ou seja, a linguagem assemelha os fenômenos biológicos às funções dos sistemas intencionais humanos com deliberação e consciência.

As ideias apresentadas motivaram o presente estudo que teve os seguintes eixos norteadores: I) considerando o fenômeno biológico "polinização", até que ponto alguns termos, aparentemente "finalistas", podem ser usados em textos científicos sem que ocorra um prejuízo no entendimento de questões ontogenéticas e filogenéticas; II) como a linguagem teleológica pode ser incluída em um sequência didática que permita reflexões sobre a Epistemologia da Biologia, ou seja, como se constrói o conhecimento biológico.

\section{Duas concepções filosóficas sobre função: Larry Wright e Robert Cummins}

No contexto da Filosofia da Biologia, há uma divisão fundamental entre as interpretações filosóficas sobre o conceito de função. De um lado, os autores que defendem as ideias teleológicas de função, seguindo a concepção etiológica defendida por Larry Wright em seu artigo Functions, publicado em 1973. De outro lado, os autores que não aceitam essas ideias, considerando o artigo Functional analysis (1975) de Robert Cummins como um marco da concepção organizacional dentre as ideias não-teleológicas.

$\mathrm{O}$ uso da linguagem teleológica é diferente em vários autores. Para Cummins, o importante ao se trabalhar com as questões sobre função não é a existência ou presença de certo item ${ }^{2}$ (podendo ser um organismo ou uma característica desse organismo), como proposto por Wright. Mas, a capacidade que cada item tem dentro de um sistema complexo. A função seria algo de que se faz uso para explicar a capacidade de um sistema que o contém, não para explicar por que algum item existe em tal sistema ${ }^{12}$.

Wright desenvolveu as ideias sobre uma concepção de função que resguardava a originalidade de sua época. Para ele, "a controvérsia girava em torno de o que a função de alguma coisa quer dizer"13. Assim, o problema sobre a ideia de função na Biologia não estaria nas respostas, e sim, nas perguntas. Wright, por exemplo, afirmava que as perguntas feitas pela ciência eram questões do tipo "algo é bom a quê?", enquanto que a pergunta correta deveria direcionar a uma resposta sobre a função de algo (a explicação funcional), ou seja, "por que algo existe?"13.

Em seu trabalho, Wright discorre sobre a distinção entre o que poderia ser chamado de "função" e o que seria o acidente realizado por algo. A função "natural" seria o que algo realizaria e que justificaria a sua existência, o que teria sido selecionado por um processo evolutivo, pela seleção natural. Acidentes seriam as outras atividades que algo realizaria, mesmo que não justificasse sua existência ${ }^{13}$.

Um exemplo utilizado pelo autor para mostrar a diferença entre o que seria a função de determinado objeto e o que seriam as "outras coisas" que esse objeto executaria é depreendido de sua afirmação: "um absurdo dizer que a função do nariz humano é servir de apoio para os óculos"13. Segundo Wright, a função do nariz seria relacionada a manter o ar seco ou úmido que seres humanos respiram; e, apoiar os óculos seria uma utilidade do nariz além de sua função, ou seja, uma atividade acidental, que aconteceria apesar de não justificar sua existência ${ }^{13}$.

Wright disserta que para as funções naturais serem explicadas seria necessário o entendimento sobre o processo de seleção natural ${ }^{13}$. Para ele, somente fazendo referência à origem evolutiva seria possível explicar porque $\mathrm{X}$ estaria ali e possuía uma função particular: "apenas dizer que $X$ possui uma função, isso já é oferecer uma importante explicação sobre X"13. Ainda assim, "toda função é uma consequência, mas há consequências que não são funções"13. Por isso, sua análise foi considerada por ele próprio como "etiologia da consequência" (consequence-etiology) ${ }^{12}$.

Na visão geral de Wright (1973), ele assume que a função de determinado traço explicaria a continuação de sua existência. Se um sistema apresentasse um traço, a função desse traço seria a razão por ele estar presente nesse sistema. Para Wright, dizer que a função de $X$ é $Z$ significa afirmar que $X$ está ali porque faz Z e Z é uma consequência (o resultado) de X estar ali ${ }^{13}$. A função de algo seria aquela coisa particular para a qual ela serve e isto explica por que este algo estaria presente $^{13}$.

Nesse sentido, é possível depreender que a visão de função de Wright possui um caráter teleológico e evolutivo. Para ele, todos seres vivos poderiam ser formados com a expressão "de modo que" ou "a fim de que" e, assim, explicar por que razão certa coisa cumpre certa função. Isso seria mais que apontar para a utilidade dessa coisa, pois uma coisa pode ser inútil 
ou defeituosa e ainda assim ter mantida sua função. Além disso, pode haver utilidade em um item sem que essa seja sua função ${ }^{14}$.

Cummins (1975) defende a proposta de excluir os enunciados teleológicos das Ciências Naturais, em especial da Biologia e defende uma interpretação específica do conceito de função biológica e das explicações funcionais. $\mathrm{O}$ autor ressalta a ideia de que função é uma explicação causal específica de algo. Para ele, atribuir função a algo é atribuí-lo de uma capacidade que é apontada por seu papel na análise sistêmica que o contém ${ }^{15}$. Ou seja, o poder explicativo de função está na avaliação de sua contribuição para o sistema do qual o ente faz parte, o que não é relevante para sua compreensão a informação sobre sua origem $^{11}$.

A ideia geral de função em Cummins é que as atribuições funcionais são asserções explicativas ${ }^{15}$. Sua análise funcional foi formalizada por ele da seguinte forma: [...] x funciona como $\Phi$ em s (ou: a função de $\mathrm{x}$ em $\mathrm{s}$ é $\Phi)$ relativo à uma abordagem analítica $A$ da capacidade de s de $\Phi$, apenas caso x seja capaz de $\Phi$ em s e A dê conta da capacidade de $\Phi$ em parte mediante um recurso à capacidade de x fazer $\Phi$ em $\mathrm{s}^{15}$.

Atribuir uma função a algo, para Cummins, significa atribuir uma disposição, uma "regularidade disposicional" 15 . Em outras palavras, seria dizer que todas as vezes que $\mathrm{x}$ fosse colocado na situação $\mathrm{s}$, ele realizaria $\Phi$, uma vez que a função de x é $\Phi$. Nesse sentido, considerar que algum organismo possui a função de executar alguma ação ou participar de algum fenômeno em determinado ecossistema significa dizer que o organismo se comportará de modo a apresentar esta função sempre que colocado sob determinado ecossistema, apresentando determinado padrão regular quando exposto àquela disposição ${ }^{15}$.

Segundo Cummins, para determinar a função de um sistema seria necessário decompô-lo em partes e definir a função de cada uma de suas partes. Por meio de uma estratégia analítica, que consiste em analisar a disposição de um elemento a partir de outras disposições que esse elemento possa ter, seria explicar a capacidade do todo a partir da capacidade de suas partes ${ }^{15}$.

Cummins discute função como a relação entre meios e fins. Possui uma abordagem a-histórica, ou seja, pautada pela observação da capacidade de algo no presente, desconsiderando a história evolutiva do item e a linguagem teleológica. Para Cummins, o que o organismo faz é determinado pelo plano genético característico de sua espécie. Esse plano não é determinado nem alterado pela seleção natural, mas por mutação e recombinação ${ }^{11}$.

Ao afirmar que "uma capacidade complexa de um organismo pode ser explicada mediante ao apelo à análise funcional, independentemente de como essa capacidade se relaciona à capacidade do organismo de manter a espécie", Cummins mostra que sua ideia de explicação funcional se dá de forma independente às considerações evolutivas ${ }^{15}$.

As duas visões sobre função, segundo Wright e segundo Cummins, apresentam ressalvas e comentários de melhorias feitas por outros autores $^{16,17,18,2,12,7}$.

A visão de Wright é criticada ${ }^{2,16,7}$ por afirmar que a função não pode explicar o porquê de algo existir, uma vez que algo deve existir primeiro para depois possuir uma função. $\mathrm{O}$ adequado seria explicar que algo existe pelo seu desenvolvimento e não somente pela sua função, ou seja, a função de algo não é o porquê de ele existir, mas, é o porquê desse algo ser fixado na população, randomicamente, por seleção natural. A crítica à análise de Wright permanece, pois, sua visão é ainda considerada estritamente selecionista. No entanto alguns estudos já sinalizam que a seleção natural não é o único meio de fixação de determinada característica na população ${ }^{12}$.

Apesar das críticas dirigidas à análise de função biológica a partir da associação entre teleologia e adaptação, tal abordagem ainda encontra muitos defensores ${ }^{17,1,2,19}$.

Sobre as ideias de função de Cummins também são apresentadas algumas contestações. As críticas referem-se ao caráter reducionista, como as elucidadas por Millikan ${ }^{17}$, e à falta de um viés evolutivo, como contestado por Kitcher ${ }^{18}$. Além disso, o autor não define em sua tese sobre as explicações funcionais qual sistema ele se refere e qual capacidade que o item deva cumprir nele. Ainda, Cummins não diferenciou "função" de "acidente", o que aparentemente parece um fator fundamental na discussão sobre explicações funcionais $^{12}$.

De acordo com Chediak ${ }^{11}$, há tentativas de unificação dessas duas concepções. Mossio e colaboradores $^{20}$ admitem que as duas tradições, disposicional e etiológica, têm sido discutidas e suas qualidades e limitações têm sido analisadas por muitos autores. Esses autores parecem concordar que são visões não excludentes por apresentarem concepções do conceito de função complementares.

As literaturas filosóficas mais recentes sobre função têm tentado unificar as duas visões, de Wright e Cummins, em um único quadro conceitual ${ }^{20}$. Apesar de algumas diferenças terminológicas, Mossio e colaboradore ${ }^{20}$ reconhecem que a ideia central dessas abordagens possui uma relação teórica: a ideia organizacional instanciada por sistemas vivos fornece uma base adequada para funções naturais. No entanto, os autores defendem que essa ideia não teve muito sucesso na construção de um relato satisfatório e isso pode ter sido o motivo pelo qual esses trabalhos pouco ecoaram na literatura filosófica ${ }^{20}$.

Chediak $^{19}$, entretanto, sugere que se aplique cada tipo de linguagem à um tipo específico de explicação, relacionando a linguagem teleológica às pesquisas em Ecologia e Evolução, enquanto que a não-teleológica ao campo da Fisiologia, por exemplo. 
Explicações funcionais na Biologia e o fenômeno polinização: uma proposta didática

O problema da existência ou não de fenômenos teleológicos na Biologia se relaciona com os dois tipos de explicação de fenômenos que nela convivem: as explicações que remetem às causas próximas e as explicações que envolvem causas distantes ${ }^{21}$.

Para $\mathrm{Mayr}^{22}$, todo fenômeno ou processo em organismos vivos é resultado de duas causas separadas, chamadas de causas próximas, ou funcionais, que ocorrem no nível ontogenético, dos indivíduos; e de causas últimas ou evolutivas, que ocorrem no nível filogenético, da população.

No contexto do presente artigo, o fenômeno polinização foi usado como objeto de estudo, um exemplo para análise da linguagem teleológica na Biologia.

As síndromes de polinização fornecem um conjunto de informações que auxilia no estabelecimento da relação entre o tipo de recurso produzido pela flor, sua forma, tamanho, cor, perfume, momento de antese e liberação de recurso (pólen ou néctar) e quais seriam os vetores de pólen com maiores chances de reconhecer a flor, encontrar e coletar tal recurso com comportamento adequado à polinização $0^{23}$.

Para Caponi $^{24}$, indicar uma espécie como polinizadora não é indicar que ela viva da polinização pois, nenhuma espécie vive de prestar serviço à outra; mas implica em atribuir a ela uma função dentro do processo de polinização de outras espécies. Outra questão seria afirmar que "para determinada planta esse inseto é um polinizador mais eficiente do que outro", o que significaria dizer que "seu comportamento e sua morfologia promovem essa polinização com maior segurança e frequência"24. Mas, não se pode dizer que a maior eficiência no cumprimento dessa função seja o efeito de um processo de desenho $^{2}$; ela não surgiu de esforços sucessivos de seu incremento progressivo, mas como resultado da seleção natural ${ }^{24}$.

Para Caponi ${ }^{24}$, tanto plantas quanto insetos viramse beneficiados por essa evolução, resultante não necessariamente de coevolução, mas de duas pressões seletivas distintas e independentes. Portanto, não se pode dizer que os "insetos estejam desenhados em virtude de um incremento de sua eficácia como polinizadores", mas, "que estão desenhados em virtude da proteção mimética que a sua morfologia outorga" 24 . Ao assumir que a meta de todo organismo é estabelecer e preservar sua autonomia organizacional perante as contingências e perturbações do entorno, pode-se dizer que cabe caracterizar como "funcional" qualquer efeito de uma estrutura ou processo que contribua para a autossustentação e reprodução ${ }^{24}$.

Muitos filósofos da ciência fazem afirmações a respeito das bases biológicas com considerações epistemológicas em geral ${ }^{1}$. Assim, uma perspectiva centrada nas discussões históricas e epistemológicas do conhecimento biológico vem constituindo uma importante prática para enfrentar o ensino fragmentado e possibilitar a necessária integração didática entre suas diferentes áreas, a partir de uma abordagem intradisciplinar ${ }^{25}$.

$\mathrm{Na}$ busca pela construção racional do conhecimento científico existem possibilidades de aliar estudos disciplinares a outras formas interdisciplinares de estudo e reflexão, em que alunos em formação inicial tenham a oportunidade de estudar o conhecimento biológico, inter-relacionando suas especificidades, formulando questões sobre a natureza desse conhecimento e planejando pesquisas na área de Biologia e suas interfaces ${ }^{26}$.

Em 1995, Matthews ${ }^{27}$ argumentava que a História, Filosofia e Sociologia da Ciência (HFS) podem humanizar as ciências e aproximá-las dos interesses pessoais, éticos, culturais e políticos da comunidade; podem tornar as aulas de ciências mais desafiadoras e reflexivas, permitindo, deste modo, o desenvolvimento do pensamento crítico; podem contribuir para um entendimento mais integral de matéria científica, isto é, podem contribuir para a superação do "mar de falta de significação" que se diz ter inundado as salas de aula de ciências, onde fórmulas e equações são recitadas sem que muitos cheguem a saber o que significam; podem melhorar a formação do professor auxiliando o desenvolvimento de uma Epistemologia da Ciência mais rica e mais autêntica, ou seja, de uma maior compreensão das estruturadas ciências, bem como do espaço que ocupam no sistema intelectual das coisas ${ }^{27}$.

Segundo Matthews ${ }^{28}$, ter nas escolas uma abordagem filosófica-histórica como ferramenta ao ensino de ciências é essencial para entender e solucionar adequadamente muitos dos debates teóricos do atual cenário educacional, pois, podem contribuir para temas mais práticos e pedagógicos, tais como o desenvolvimento do currículo e a prática docente em sala de aula.

Entende-se ainda que alguns dos pontos fundamentais na elaboração de um pensamento epistemológico no contexto de ensino de Biologia na graduação seja, além de considerar a inserção da Filosofia da Biologia, possibilitar os estudos de autores que pesquisaram em diferentes áreas do conhecimento biológico e suas interfaces e analisar a produção do conhecimento biológico, por meio de conceitos oriundos dessa Filosofia em específico ${ }^{26}$.

$\mathrm{O}$ valor heurístico da linguagem teleológica tornase uma interessante ferramenta na análise dos fenômenos biológicos, desde o estudo da configuração estrutural das macromoléculas até o estudo de comportamento cooperativo em sistemas sociais ${ }^{5}$, haja vista a necessidade de cautela ao se redigir um texto científico, evitando termos que possam conotar um sentido pejorativo das ideias teleológicas. 
Desse modo, um dos fenômenos biológicos interessantes para ser utilizado em aulas de Ciências e Biologia, por envolver conteúdos de diversas áreas do conhecimento biológico é a polinização. Por exemplo, na Botânica em estudos das partes das plantas; na Entomologia e na Zoologia de forma geral, considerando as estruturas dos corpos dos animais polinizadores; na Ecologia, considerando as ideias sobre interações ecológicas e serviços ecossistêmicos (Por serviços ecossistêmicos ou serviços ecológicos entende-se os possíveis usos da natureza pelos seres humanos para qualquer fim. Os processos e ambientes físico que são úteis para os seres humanos que podem ser utilizados de forma direta ou indireta e serem usados tanto para o consumo quanto para outros bens de capital ${ }^{29}$ ).

Ao longo do século XX, especialmente a partir da década de 1970, o desenvolvimento da Paleobotânica, Morfologia e Fisiologia vegetal, Citologia, Genética, Evolução e Ecologia favoreceram uma nova área de pesquisa, a Biologia da Polinização ${ }^{30}$.

Roubik $^{31}$ afirma que "a relação ecológica entre abelhas e plantas com flores são dependentes (dependent) de vários parâmetros físicos do ambiente e do modo como as abelhas percebem e respondem a eles" "31. Sobre a importância de estudos que tratem dessas questões, o autor justifica que "a ecologia da polinização tropical fornece um impulso para o estudo da biologia reprodutiva das plantas através da diversidade de interações" $" 31$.

Kremen e colaboradores ${ }^{32}$ trazem um enfoque no papel (use) das abelhas aos serviços ecossistêmicos, sobre a necessidade de conservação da biodiversidade diante da intensificação da agricultura e o impacto causado pela redução na abundância das abelhas para um futuro econômico e ecológico.

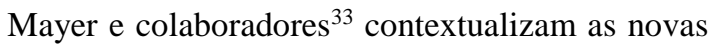
tendências de pesquisa sobre polinização no século XXI. Para os autores, "o declínio global da biodiversidade e a destruição e degradação dos habitats, assim como as mudanças climáticas decorrentes das atividades humanas, acabam afetando a relação planta - polinizador" ${ }^{33}$.

$\mathrm{Na}$ busca por promover discussões e reflexões sobre a linguagem teleológica no ensino de Biologia o presente artigo procurou o planejamento $\mathrm{e}$ delineamento de uma intervenção didática, tomando como aporte teórico a ferramenta "Teaching-Learning Sequences" (TLS), desenvolvida por Mehèut ${ }^{34}$. Segundo a autora, o planejamento é feito a partir de quatro componentes básicos: o professor, os alunos, o mundo material e os conhecimentos científicos (FIGURA 1).

A importância da TLS proposta por Mehéut ${ }^{34}$ consiste na consideração de duas dimensões: a dimensão epistêmica na qual são explicitados os processos de elaboração, métodos e validação do conhecimento e sua significação com relação ao mundo real; e a dimensão pedagógica, que considera os aspectos relativos ao papel das interações entre professor e alunos e dos alunos entre si.

A proposta desta intervenção é direcionada ao curso de graduação em Ciências Biológicas e tem como tema "Linguagem e o ensino sobre a polinização", podendo ser aplicada em disciplinas que resguardam afinidades com o assunto e que seja previamente acordada entre pesquisador e docente. Trata-se de uma prática reflexiva que fomenta a discussão dos alunos sobre a linguagem teleológica no ensino.

Esta atividade permite avaliar e investigar, por meio dos argumentos utilizados para justificar as decisões tomadas, em que medida a sequência didática (SD) contribui para facilitar a abordagem da temática da linguagem funcional em sala de aula, tendo como exemplo o fenômeno polinização.

Buscando diretrizes para a SD, o pesquisador pode discutir com o docente da disciplina suas concepções acerca do tema, abrindo espaço para interações professor-pesquisador durante a atividade.

Inicialmente, os alunos recebem apenas o material distribuído pelo pesquisador e utilizam apenas suas percepções e conhecimentos prévios para a tomada da decisão a ser solicitada.

A SD proposta se constitui de três etapas:

- Primeira etapa: os alunos são expostos a quatro textos científicos de diferentes épocas que discorrem sobre o fenômeno polinização.

O primeiro texto traz a descrição do fenômeno sob a visão e linguagem utilizadas pelo botânico alemão Christian Konrad Sprengel (1750 - 1816). Segundo Proctor $^{30}$, Sprengel foi o "fundador" [founder] dos estudos sistemáticos sobre a relação entre insetosplantas. Para esta proposta foi adotada uma tradução em inglês da obra Das entdeckte Geheimniss der Natur im Bau und der Befruchtung der Blumen [Descobrimento dos segredos da natureza nas estruturas e fertilização das flores $]^{35}$, feita por Peter Haase no livro Floral Biology: study on floral evolution in animal pollinated plants [Biologia Floral: estudo da evolução floral em plantas polinizadas por animais $]^{36}$.

O segundo texto aborda a visão de Charles Robert Darwin (1809 - 1882) no capítulo X intitulado The means of fertilisation [Os meios de fertilização], da obra The effects of cross and self fertilisation in the vegetable kingdom [Os efeitos da fertilização cruzada e da autofertilização no reino vegetal $]^{37}$. Refere-se às observações feitas acerca da redução do número de sementes produzidas pelas flores quando estas estavam fenologicamente impossibilitadas às visitas dos insetos ${ }^{30}$. 


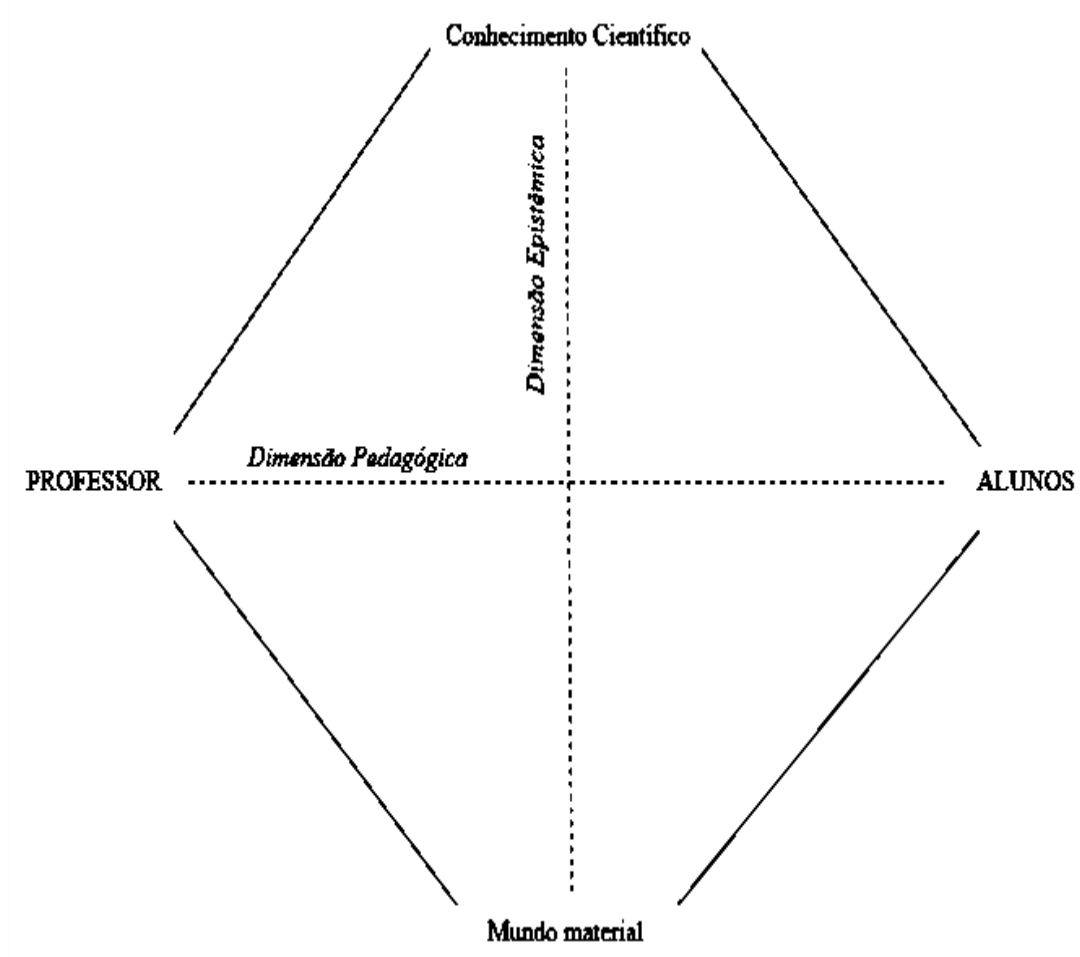

FIGURA 1: Elementos considerados para construção da sequência didática, e os eixos contemplados no desenvolvimento da atividade (Modificado de Mehèut ${ }^{34}$ ).

O terceiro texto foi escrito em uma época em que a Biologia da Polinização se concretizou como uma nova área de pesquisa ${ }^{30}$. Nesse contexto, o cientista do Smithsonian Tropical Research Institute [Instituto de pesquisas tropicais de Smithsonian], David Ward Roubik, escreveu o capítulo 2 intitulado Foraging and pollination [Forrageamento e polinização], de seu livro Ecology and Natural History of Tropical Bees [Ecologia e história natural das abelhas tropicais] ${ }^{31}$. Nesse texto, Roubik discorre sobre a influência [influence] das abelhas no fitness reprodutivo das plantas e a diversidade de interações, bem como os fatores que podem afetar a "efetividade" do processo $^{31}$.

O quarto texto traz uma visão contemporânea, relacionando a polinização com mudanças climáticas e perda da biodiversidade ${ }^{33}$. Claire Kremen, bióloga americana, docente na Universidade da Califórnia (Berkeley, EUA), escreveu junto com seus colaboradores, o artigo intitulado Pollination and other ecosystem services produced by móbile organisms: a conceptual framework for the effects of land-use change [Polinização e outros serviços ecossistêmicos produzidos por organismos móveis: um quadro conceitual dos efeitos às mudanças do uso da terra $]^{32}$.

Esses quatro textos são entregues anonimamente aos estudantes, ou seja, eles não têm acesso inicialmente ao nome dos autores utilizados nesta etapa da atividade. Eles devem se ater às linguagens utilizadas em cada texto e às respectivas facilidades e/ou dificuldades de entendimento aos termos presentes em cada texto.

- Segunda etapa: após a leitura dos textos, os alunos devem se manifestar sobre suas percepções e seus pontos de vista sobre cada texto. Em seguida, devem responder a seguinte questão: "Considerando a linguagem utilizada em cada texto, qual deles você utilizaria como futuro professor para explicar o fenômeno biológico polinização? Por quê’’?

É preciso salientar que em todos os textos é possível encontrar, de diferentes formas, alguns termos "aparentemente finalistas" remetendo a ideia de propósito e finalidade do fenômeno. Assume-se que o uso de termos teleológicos não deve necessariamente ser considerado um erro na descrição do fenômeno, desde que os autores deixem claro os aspectos fisiológicos e os aspectos evolutivos acerca do fenômeno ${ }^{38,39}$. Os textos foram escritos em diferentes épocas, nas quais se verifica uma mudança de ideias sobre as explicações funcionais, o que permite dizer que o termo "função" apresenta diversos significados em diferentes contextos de Ciência. Conforme exposto anteriormente, concorda-se com a redução do uso de termos teleológicos em textos científicos, pois, diante tantas interpretações dos termos pode-se gerar entendimentos equivocados, voltados às visões antropocêntricas e/ou teológicas, que não são consideradas ao ensino de ciências.

- Terceira etapa: após a escolha do artigo e a apresentação de justificativas, é proposta uma roda de discussão com todos envolvidos: pesquisador, professor e alunos. 
As ideias filosóficas sobre linguagem teleológica na ciência são esclarecidas sob pontos de vista dos autores Wright ${ }^{13}$ e Cummins ${ }^{15}$. Outras ideias também podem ser discutidas nesta etapa, referentes aos aspectos pertinentes às dimensões epistêmicas e pedagógicas que permeiam a intervenção didática, como por exemplo, sobre as implicações e problemas envolvidos no uso da linguagem teleológica na Ciência, em especial, na Biologia, bem como as formas de superação às lacunas dessa linguagem no ensino.

Os resultados ao final da atividade proposta são reunidos em uma tabela em que se pode estabelecer uma comparação das concepções iniciais e finais do processo de desenvolvimento do conhecimento acerca da temática abordada na formação inicial. É o que Mehéut denomina de validação interna ${ }^{34}$.

A importância dessa discussão é abordada por Sepulveda e colaboradores ${ }^{40}$ que defendem uma atitude mais positiva em relação à linguagem funcional no ensino de ciências: a) o valor heurístico dessa aproximação reside em permitir que os estudantes se aproximem dos fenômenos biológicos e em possibilitar que professores e estudantes se comuniquem a respeito desse fenômeno em sala de aula; b) o valor pedagógico permite que estas formulações surjam, criando-se oportunidades para discutir seu significado, tanto durante as aulas quanto em leituras de termos teleológicos em livros didáticos ${ }^{41} \mathrm{e}$, desse modo, alcançar uma melhor compreensão, inclusive no que diz respeito à distinção entre formulações teleológicas válidas e inválidas em seu contexto.

\section{Conclusão}

Apresentar uma abordagem filosófica-histórica no ensino de Biologia pode ser considerado pertinente ao entendimento de conceitos biológicos, contribuindo para a construção contextualizada do conhecimento e da prática docente em sala de aula.

A Filosofia da Biologia integra noções epistemológicas que são expressas tanto nas ideias dos textos científicos tratados neste estudo, como na visão dos professores e alunos diante dos processos evolutivos e das características fisiológicas que envolvem os fenômenos biológicos.

A escolha da ferramenta "Teaching Learning Sequence" se mostrou adequada à proposta didática uma vez que busca integrar os conhecimentos e concepções de todos os participantes envolvidos na atividade, gerando aproximações tanto na relação professor-aluno quanto ao conteúdo biológico a ser ensinado, contribuindo para o processo ensinoaprendizagem.

Considerando o ensino de Biologia, considera-se necessária a redução no uso de termos finalistas e/ou teleológicos, uma vez que a sua utilização poderia gerar um entendimento equivocado sobre os fenômenos que são estudados à luz das teorias evolutivas, como por exemplo, a interpretação de que a polinização ocorre devido à uma intenção dos animais e plantas ou de um "ser projetor" e não decorrente da seleção natural (ou outros fatores evolutivos).

Entende-se que, em alguns casos, alguns termos "aparentemente finalistas" são utilizados, como é o caso dos estudos fisiológicos dos fenômenos. Entretanto, recomenda-se que esses estudos sejam tratados de modo contextualizados, abordando os aspectos ontogenéticos e filogenéticos do fenômeno.

Este estudo mostrou a necessidade de desenvolvimento de estratégias didáticas como a proposta apresentada, levando ao entendimento da pertinência de uma didática específica para o tratamento do conhecimento biológico, a partir de abordagem Intradisciplinar.

Desse modo, o estudo se apresenta como base para a implementação de uma intervenção didática em cursos de licenciatura em Ciências Biológicas que poderá viabilizar reflexões acerca da construção do conhecimento biológico, gerando narrativas conscientes por parte dos professores em formação inicial, considerando inserções tanto históricas quanto epistemológicas.

\section{Declaração de conflitos de interesses}

Os autores do artigo afirmam que não houve nenhuma situação de conflito de interesse, tais como propostas de financiamento, emissão de pareceres, promoções ou participação em comitês consultivos ou diretivos, entre outras, que pudessem influenciar no desenvolvimento do trabalho.

\section{Referências}

1- GRIFFITHS, P. E. (2011). Philosophy of Biology. In: E. N. ZALTA (Ed.) Stanford encyclopedia of philosophy. Disponível em https://plato.stanford.edu/entries/biology-philosophy/, Estados Unidos: Editorial Board.

2- GODFREY-SMITH, P. (1998[1994]). A modern history theory of functions. In C. ALLEN, M. BEKOFF, G. LAUDER (Eds), Nature's purposes analyses of function and design in biology (p. 453478). Cambridge: MIT Press.

3- JOHNSON, M. R. (2005). Aristotle on teleology. Oxford: Clarendon Press.

4- MARTINS, R. (2013a). A doutrina das causas finais na Antiguidade. 1. A teleologia na natureza, dos présocráticos a Platão. Filosofia e História da Biologia, $8(1), 107-132$.

5- GARSON, J. (2011). Function and Teleology. In S. SARKAR, A. PLUTYNSKI (Eds). A companion to the philosophy of Biology (p.525-549). Nova Jersey: Editora Wiley-Blackwell.

6- MAYR, E. (1988). Toward a new philosophy of biology. Estados Unidos: Library of congress cataloging in publication data. 
7- MARTINS, R. (2013b). A doutrina das causas finais na Antiguidade. 2. A teleologia na natureza, segundo Aristóteles. Filosofia e História da Biologia, 8(2), 167-209.

8- MAYR, E. (1992). The idea of teleology. Journal of the history of ideas, 53(1), 117-135.

9- CUMMINS, R. (2010). Neo-Teleology. In A. ROSENBERG, R. ARP (Eds.), Philosophy of Biology an anthology (p.157-172). Nova Jersey: Editora Wiley-Blackwell.

10- MAYR, E. (1998). O desenvolvimento do pensamento biológico: diversidade, evolução e herança. Brasília: Editora UnB.

11- CHEDIAK, K. (2008). Filosofia da Biologia. Rio de Janeiro, RJ: Editora Zahar.

12- NUNES-NETO, N. F.; El-Hani, C. N. (2009). O que é função? Debates na filosofia da Biologia contemporânea. Scientiae studia, 7(3), 353-401.

13- WRIGHT, L. (1973). Functions. The philosophical review, 82(2), 139-168.

14- CHEDIAK, K. (2006). Análise do conceito de função a partir da interpretação histórica. Filosofia e História da Biologia, 1(1), 161-174.

15- CUMMINS, R. (1975). Functional analysis. The Journal of Philosophy, 72(20), 741-765.

16- GOULD, S. J. \& VRBA, E. S. (1982). Exaptation - A Missing Term in the Science of Form. Paleobiology, 8(1), 4-15.

17- MILLIKAN, R. (1989). In defense of proper functions. Philosophy of science, 56(2), 288-302.

18- KITCHER, P. (1998[1993]). Function and design. In C. ALLEN, M. BEKOFF, G. LAUDER (Eds), Nature's purposes - analyses of function and design in biology (p. 479-503). Cambridge: MIT Press.

19- CHEDIAK, K. (2011). Função e explicações funcionais em Biologia. In P. C. ABRANTES (Org). Filosofia da Biologia (p.83-96). Porto Alegre, RS: Editora Artmed.

20- MOSSIO, M.; SABORIDO, C. \& MORENO, A. (2009). An organizational account of Biological Functions. British Journal of Philosophy Science, 60(1), 813-841.

21- FERREIRA, M. A. (2003). A teleologia na biologia contemporânea. Scientiae Studia. 1(2), 183193.

22- MAYR, E. (1997). Evolution and diversity of life: selected essays. $5^{\mathrm{a}}$ ed. Estados Unidos: Harvard University Press.

23- TOREZAN-SILINGARDI, H. M. (2012). Flores e animais: uma introdução à história natural da polinização. In K., DEL-CLARO \& H. M., TOREZAN-SILINGARDI (Orgs), Ecologia das interações plantas-animais: uma abordagem ecológica evolutiva. (p.113-139). Rio de Janeiro: Techinical Books.

24- CAPONI, G. (2012). Função e desenho na biologia contemporânea. São Paulo, SP: Editora 34.
25- BRANDO, F. R., ANDRADE, M. A. B. S., MEGLHIORATTI, F. A. \& CALDEIRA, A. M. A. (2012). Contribuições da epistemologia e da história da ecologia para a formação de professores e pesquisadores. Filosofia e História da Biologia, 7(2), 181-200.

26- CALDEIRA, A. M. A. (2009). Didática e epistemologia da Biologia. In A. M. A. CALDEIRA, E. S. N. N. ARAÚJO (Orgs.), Introdução à Didática da Biologia (p. 65-79). São Paulo, Editora Escrituras. 27- MATTHEWS, M. R. (1995). História, Filosofia e Ensino de Ciências: a tendência atual de reaproximação. Caderno Catarinense de Ensino de Física, 12(3), 164-214.

28- MATTHEWS, M. R. (2002). O tempo e o ensino de ciências: como o ensino da história e filosofia do movimento pendular pode contribuir para a alfabetização científica. In W. J. SILVA-FILHO (Org.) Epistemologia e Ensino de Ciências. Salvador: Editora Arcádia.

29- HUETING, R., REIJNDERS, L., BOER, B., LAMBOOY, J. \& JANSEN, H. (1998). The concept of environmental function and its valuation. Ecological Economics, 25(1), 31-35.

30- PROCTOR, M.; YEO, P. \& LACK, A. (1996). The natural history of pollination. Sydney, Austrália: Harper Collins Publisher.

31- ROUBIK D. W. (1989). Ecology and natural history of tropical bees. Cambridge: Cambridge University Press.

32- KREMEN, C., WILLIAMS, N. M., AIZEN, M. A., GEMMILL-HERREN, B., LEBUHN, G., MINCKLEY, R. RICKETTS, T. H. (2007). Pollination and other ecosystem services produced by mobile organisms: a conceptual framework for the effects of land-use change. Ecology Letters, 10(1), 299-314.

33- MAYER, C., ADLER, L., ARMBRUSTER W. S., DAFNI, A., EARDLEY, C., HUANG, S. Q. POTTS, S. G. (2011). Pollination ecology in the 21st century: key question for future research. Journal of Pollination Ecology, 3(2), 8-23.

34- MEHÈUT, M. (2005). Teaching-Learning Sequences Tools for learning and/or research. In K. BOERSMA, M. GOEDHART, O. JONG \& H. EIJKELHOF (Eds.), Research and the Quality of Science Education, Netherlands: Springer International Publishing.

35- SPRENGEL, C. K. (1996[1793]). Das entdeckte Geheimniss der Natur im Bau und der Befruchtung der Blumen. Tradução de HAASE, P.: Discovery of the secrets of nature in the structure and fertilization of flowers. In: D. G., LLOYD \& S. C. H., BARRETT (Eds.) Floral Biology: Studies on floral evolution in animal-pollinated plants (p. 3-43). New York: Editora Chapman \& Hall.

36- LLOYD, D. G. \& BARRETT, S. C. H. (Eds.) (1996). Floral Biology: Studies on floral evolution in animal-pollinated plants. New York: Editora Chapman \& Hall. 
37- DARWIN, C. R. (1878). The effects of cross and self fertilisation in the vegetable kingdom. London: John Murray, Albemarle Street.

38- D’AMBROSIO, M; BIZZO, N; SANTOS, F. S. (2018) Difficulties in teaching evolution due to the influence of teleology. Filosofia e História da Biologia, v. 13, n. 2, p. 191-206.

39- CESCHIM, B. (2017) O emprego da Teleologia na interpretação da Biologia Funcional e Evolutiva: um estudo a respeito de concepções e da evolução conceitual de alunos de licenciatura em ciências biológicas. Dissertação apresentada ao Programa de Pós-Graduação em Educação para a Ciência, para obtenção do título de Mestre em Educação para a Ciência. Faculdade de Ciências, Universidade Estadual Paulista "Júlio de Mesquita Filho" (Unesp Campus Bauru), 224f.

40- SEPULVEDA, C., NUNES-NETO, N.; ELHANI, C. N. (2011). O valor heurístico e pedagógico da linguagem teleológica no ensino de evolução. In Anais do VIII Encontro Nacional de Pesquisa em Educação em Ciências. (p. 1-13). Campinas, SP.

41- CARMO, R. S.; NUNES-NETO, N. F.; EL-HANI, C. N. (2016). Teleologia, função e ensino de Biologia. Acta Scientiae, v.18, n.3. 